\title{
Kindergarten Regional Activities: Trends and Problems
}

\section{Chongli Wang ${ }^{1}$}

\author{
${ }^{1}$ School of Education Science, Huaiyin Normal University, Huaian, Jiangsu, 223300 \\ hunter2011@foxmail.com
}

Keywords: Trends; Problem; Kindergartens Regional Activities

\begin{abstract}
Because of its rich environment to meet children autonomy, freedom of exploration activities, personalized learning, Kindergarten regional activities have become early childhood favorite game. Throughout its development, we found that it still exists in the target area of activity that it is not expressly provided; environmental settings "polarization"; lack of material; guidance arbitrarily oriented; Evaluation neglect of other issues. Based on local reality, combined with the international trend, the regional development of the game will be presented: A comprehensive regional activities, environmental setting life, material provides "life" and the guidance of professional evaluation, "the story" of the trend. This article is designed to help preschool teachers change from concept to behavior, so that the children can grow up happy in the game.
\end{abstract}

\section{Introduction}

Regional activities thought originated in the West, since the early 1990s, the area from overseas students introduced to the domestic game modes, a time zone in the country nursery game flourished. Many nursery children activity room is divided into different areas, and are arranged to be "regional" activities. But through its booming phenomenon, we should see a rational regional games still exist many problems. We need to sort out from the reality of the problems, establish the correct concept, and a clear future trend. Many studies show that the concept of teacher education teacher originally might be clear, it may be implicit, non-systematic, but affect their teaching behavior. [1] Only clear from the concept, and can really make adjustments from the behavior, child care teachers the same. This article helps kindergarten teachers expect to get change from the concept to the behavior of its effective organization, participation, involvement playgroups provide think, really let the children grow up happy in the game.

\section{The Concept of Kindergarten Regional Activities}

The so-called regional activities, is a teacher to provide some space and campaign materials for young children based on educational goals, autonomous young children in a rich environment, freedom of exploration activities and individualized learning. [2] The scope of the area are generally more extensive, including indoor space, outdoor space or community environment.

\section{The Problems of Kindergarten Regional Activities}

In kindergarten, the characteristics and the educational value of regional activities truly reflected it? In actual fact, I visited the nursery by observing the scene and found the game in kindergarten practice activities, regional activities more or less the existence of such problems:

Target Non-Explicit of Regional Activities Setting. Kindergarten teachers which area you want to set up; locale ultimately achieve what goals; by what materials to help them complete their education goals, is not clear enough. Typically, according to the development needs of preschool teachers of young children, it can be divided into different areas. Generally, nursery settings include the performance area, the construction of area, art area, library area, reading area and science area.

On the contrary, clear objectives of teachers can help children to be done to maximize the effect of regional activities, regional activities suitability class, hierarchy. In short, through regional activities to stimulate children motivated intrinsic activity, causing a positive experience, and 
regional activities by children in the process, contributed to the harmonious development of the individual mind and body, it is expected to reach the target area of activities

The Polarization of Regional Activities Environment Settings. "Polarization" epitomizes two, environment settings superficial, often based. Child activity room is superficial identify different zones corner on wall hangings also able to reflect the different regions of angles. However, in time, can not guarantee the Kids area on space activities, child care in this environment, passive adaptation, are deprived of the opportunity to explore the operation.

Teachers should consider how to take advantage of the regional gaming environment for development of young children, how to provide suitable conditions according to the level of early childhood development game, the game environment so as to avoid the creation of the "polarization" phenomenon.

Material deprivation of regional activities. Regional activities of the game material is a tool and the material basis of preschool activities, it is part of the regional environment. Games campaign materials to produce indirect impact on early childhood development by influencing the type of children's games and game content, the game material can also provide an opportunity to learn directly affect the development of young children. [3] Regional Activity material deprivation reflected in two aspects, from toys functional point of view, lack of interoperability, some campaign materials because of too simple to arouse desire playgroup; some are too difficult, so that children can not produce the game interest; some materials are "display", it can not operate.

Free of Guidance in Regional Activities. Regional activities are not children "free" activities, need adult help and guidance. However, in practice, due to the lack of systematic observations of teachers, guidance somewhat random, can not reflect the "implementation of educational, observe first." Regional activities directed "random" of usually presents the following situations:

Director of Formula One is teacher guidance, teachers in their own good circumstances envisaged requirements and guidance playgroup. For example, the area game, "KFC", the teacher informed the customer and service personnel to play, how to say, how to do it. This may result in the experience, practical experience neglected children. One is fragmented guidance. Teachers to children play area regarded as rest time, the opportunity to engage in other work, or occasionally during the game situation concerns children, often see the "fragment of the scene" as the guiding basis. Due to lack of understanding of the whole game, and can not accurately perceive the interests and needs of young children the game, and sometimes even lead to playgroup stop. The guidance of teachers and enhance the playgroup experience, enrich children game plot to protect children and other independent game fun run counter to the original intention.

Neglect of Evaluation of Regional Activities. United States early childhood professionals of civil institutions National Association of Early Childhood Education (NAEYC), as the evaluation was "observe, record activities and methods of process children, a variety of influence educational decisions on the basis of early childhood development" (NAEYC, 1991, P .32) [4] The game is a natural way to interact with the children around the world, therefore, in the process of participating in the game were evaluated for early childhood development, but also reasonable.

The game is the nature of children, children in the area of the game freely, to show their true nature, the development of early childhood teachers to understand the cognitive, emotional, social and other aspects of regional activities through the game. Game evaluation of neglect, so that teachers can not be truly "Watch playgroup performance than required children to get more information; at the same time can be observed that the performance of the situation in all areas of early childhood development." [5] Creative preschool teachers have no way of emerging in the game and share successful experiences, discuss, lazy missed develop children creative thinking good time, wasted opportunities to develop children ability to identify problems and solve problems. In addition, children in the course of the game, there will always encounter unknown problems or difficulties, some children can be a better solution, some children can not, this is precisely the difference between the performance of individual children. 


\section{The Regional Trend of Kindergarten Activities Development}

Games accompanied by early childhood development, early childhood development in the game. Games both a long history, also has its unique development prospects, the game with the continued progress and development of mankind. Kindergarten regional games with the development of the game and show a certain trend.

Regional Integration Activities. First, the game features regional diversification. This is consistent with "child development is a whole," the law; putting the "children aged 3-6 learning and development guide" (hereinafter referred to as the "Guide") spirit, that is, to "focus on the field between the mutual penetration and integration between the target and promote the coordinated development of CCDS children, and not one-sided pursuit of a particular aspect or aspects of development "; different space contains the value of early childhood development should be diversified, different areas can relate to different areas of early childhood development pursuit . For example, children not only the construction of mathematical knowledge obtained through math region. Playgroup activities in other regions through direct manipulation, direct experience to construct their own unique mathematical understanding. [6]

Second, integration of mutual penetration of the game and curriculum development echoes. Children in kindergarten is learning daily life, life is a comprehensive activity, there is no border, is holistic, integrated learning is learning in life. [7] "Regional integration is reflected in the experience of the whole child, penetrate each other from early childhood needs, experience linked to each other and the course is starting to explore the game as the mutual penetration of blood and body relationship, the game has injected vigor to the kindergarten curriculum. Curriculum made the game becomes more attractive. "[8] Many kindergartens also made in this regard and actively explore and, if combined kindergarten" Autumn Illustrated "theme, the creation of suitable bumban actual situation and actual needs of regional activities environment, In the language area, the data area, shared area matched material inputs to enrich the child care experience, make the game play a maximum value of the active area. [9] reflects the mutual penetration of the game and curriculum practices.

Relevance to Life of Environment Settings. This life of the environment should be able to recognize and respect the existence of individual life, to meet the reality of life and growth; let every child really have belongs to them, and let their lives be germination, close to reality, the real highlights Environmental body. Living and learning in such an environment, children can make a match with their needs, interests, the potential to play activities, contributed to produce a variety of effective learning activities, so that children life more dynamic, more powerful growth. "Promoting children learning environment can enrich and expand quality early childhood experiences." [10].

The game is a basic activity for children. Child care is a game for a living, the game naturally into the lives of young children. We can see from our pre-school policies and regulations, and to find relevant text confirms the instructions. For example, enacted in 1996 and the implementation of "nursery work order" that read: "educational content reasonably umbrella organization of all aspects, and the infiltration of the activities of daily life of young children, give full play to the interaction of various educational means. "" creation and education to adapt to a good environment for children activities and performance capabilities provide opportunities and conditions.

Vitality of Material Privation. "Life" is the concept of the same strain and environmental settings. Materials provided conform to the natural process of life and young children,

Children of different periods in psychological characteristics, abilities, levels are different. Children are vulnerable to environmental impact, in regional activities, teachers of young children into the material, its newness, the number of degree of difficulty, the need to adapt to the characteristics and level of development of children of age. At the same time, by providing material level, reach and children of different ages to adapt to the development of life, such as "small classes provide as vivid, bright colors, and more varieties of small quantity of finished materials; Intermediate provide quantity, variety, and a small amount of semi-finished materials; Taipan need to provide a more open, change of environment and the details of objects that reflect the 
characteristics of colorful semi-finished products and waste materials, is not fixed playgrounds and materials. "[11].

"Life" of the material lies in the material itself operability game for children in the area assigned to different functional materials, and let the material life of the glow. The educational value of the active region is mainly attached to the top of the operating area of the material. Different materials, operating methods and modalities will be different early childhood learning experiences gained in the course of nature are not the same [12].

Professional Guide. Game guide is part of the specialized professional development of preschool teachers. "Kindergarten to the game as the basic activities", Professor Hua Aihua told the audience at a lecture at the outset, "the kindergarten and primary school education the biggest difference is that the game, the game's pre-professional organization and guidance are reflected particularity." Preschool special professional reflected in the game, and urgent to improve early childhood literacy instructor in the game is an integral part of teacher professional development.

Professional guidance is based on observation. Observation provides us with the basis for playgroup guidance. [13] Through observation, it can be more comprehensive understanding of early childhood development, to understand the behavior of individual children. At the same time, global grasp playgroups process, know the game problems finding an effective solution to the problem; notes that a variety of state child care game, read and try to understand the different development needs of young children. America's early childhood education specialist• Lillian Katz (Lilian Katz) that the observation is a necessary condition to help teachers and an important way from novice to expert growth. By observing the game in the process, teachers can capture the uniqueness of each child, to impose appropriate professional help increase support children to explore and understand the sensitivity of the world. Understanding personality and stage of development of young children from the observation records, and create the environment to make adjustments, and other aspects of the material provided. Gradually develop skilled observation skills, promote early childhood game levels rose, the effective promotion of teachers' individual professional growth.

Dramatization of Evaluation. Evaluation of regional games are two-way interaction between teachers and children, through the evaluation of the construction of the game experience for young children at the same time, teachers can see the continued development of children of all abilities, change, allowing parents to understand children's special interests and experience. "Story", that children learn the story of the area to evaluate the game. "The story is a learning evaluation system for children to learn from New Zealand." [14] In our country many children in kindergarten to learn the story of life evaluation, learning, games. [15] It is not only a learning evaluation, it is also an idea, a kind of child care as the center, teachers and children working together thinking and behavior.

The story presented in evaluation of regional activities dramatization. This narrative method is used to record, evaluate and support children's learning, the focus falls on the evaluation of children's learning process. Children can be embodied in the game of learning situation. You can put the "social characteristics of learning and learning together, integrate into children's voices and emphasize children's participation and culture." [14] The evaluation can make young children to have interest in other activity.

\section{References}

[1] J. Lin. From Concept to Behavior: Science Teaching Ideas Teacher Survey And Analysis Beijing. Beijing Normal University Press, 2009: 6-7.

[2] D.M. Sun, L.Y. Huo. Waiting Kindergarten Curriculum Development and Teacher Professional Development-A Comparative Study . Beijing. Education Science Press, 2006: 126.

[3] Johnson, Eds. Early in the Game and Child Development. Shanghai. East China Normal University Press, 2006: 301. 
[4] [5] Janice J.Beaty. Observation and Evaluation of Early Childhood Development. Beijing. Higher Education Press, 2013: 7; 18.

[6] F. Wu. Children Dancing Together-Early Childhood Teachers: 50 Letter to China. Nanjing. Nanjing Normal University Press, 2006: 36.

[7] Y.P. Yu. Life is the Foundation and Source of the Kindergarten Curriculum. Early Childhood Education, 2015 (3).

[8] Q.X. Qiu. Game • Penetration • Course. Early Childhood Education, 2005 (7-8).

[9] Y.H. Gu, J.Q. Hu. Combining Effective Regional Theme Games and Activities. Preschool, 2009 (10).

[10] Rebecca Isbell, Betty Exelby. Early Learning Environments that Works. Slpver Spring MD. 2001: 11.

[11] Q.X. Qiu. Editor for the 101 Kindergarten Teachers Recommends: Game Guide . Nanjing. Nanjing Normal University Press, 2012: 70-71.

[12] X.X. Feng. The Creation and Use of Activities Area. Early Childhood Education, 1994 (4).

[13] Y. Liu. The Children's Games General Theory. Beijing. Beijing Normal University Press, 2008: 1.

[14] Margaret Carr, Wendy Lee with Learning Stubborn and Early Education: Construction Learner's Image. Nanjing. Education Science Press, 2015: 4-5.

[15] Http://www.Cnsece.Com/Kindtemplate/Msgdetail/33444, 2015.7.15. 